\title{
Didática na pós-graduação: pesquisas e produções
}

\author{
Roberto Valdés Puentes \\ Universidade Federal de Uberlândia \\ Andréa Maturano Longarezi \\ Universidade Federal de Uberlândia
}

\section{Resumo}

0 artigo analisa as pesquisas e produções sobre didática desenvolvidas nos programas de pós-graduação em Educação em Minas Gerais pela identificação das dimensões e dos campos nos quais estão concentradas; e qualifica as publicações, mediante a identificação dos veículos utilizados para sua divulgação. Os resultados indicam que: a didática ocupa, em média, um terço das pesquisas e produções realizadas; as publicações em periódicos representam pouco mais de um sexto do total; os veículos de divulgação dessa produção são pouco expressivos; e há uma concentração de estudos teóricos sobre profissionalização e formação docente, em detrimento de indagações sobre as condições e os modos de intervenção e de efetivação das práticas pedagógicas.

Palavras-chave: Didática. Campos. Dimensões. Pesquisa. Pós-graduação.

1. Este trabalho contou com o apoio financeiro do Conselho Nacional de Desenvolvimento Científico e Tecnológico - CNPq. 


\section{Didactics in graduate courses: research and production}

This article analyses the research and productions about didactics developed in Graduate Course programs in the Brazilian state of Minas Gerais, by identifying the dimensions and fields in which they are concentrated. It also qualifies their publications, by classifying and analyzing the vehicles used for their dissemination. The results indicate that: didactics consumes, on average, one third of the research and productions; publications in periodicals represent just over one sixth of the total production; the vehicles for the dissemination of this production are scientifically and academically limited; and there is a high concentration of theoretical studies about professionalization and teacher training, in detriment of inquiries about conditions and modes of intervention, and effective teaching practices.

Keywords: Didactics. Fields. Dimensions. Research. Graduate Studies.

\section{Didáctica en la post-graduación: investigaciones y producciones}

El artículo analiza las investigaciones y producciones sobre Didáctica desarrolladas en los Programas de Post-Graduación en Educación en Minas Gerais mediante la identificación de las dimensiones y de los campos en los cuales están centradas; también califica las publicaciones, mediante la identificación de los vehículos utilizados para su divulgación. Los resultados indican que: la Didáctica ocupa, en promedio, un tercio de las investigaciones y publicaciones realizadas; las publicaciones en periódicos representan poco más de un sexto del total de la producción; los vehículos de divulgación de esas producciones son poco expresivos; existencia de una concentración de estudios teóricos sobre profesionalización y formación docente, en detrimento de indagaciones sobre las condiciones y los modos de intervención y de efectivización de las prácticas pedagógicas.

Palabras clave: Didáctica. Campos. Dimensiones. Investigación. Post-graduación. 


\section{Introdução}

A didática constitui-se no principal ramo de estudos da Pedagogia, investigando os fundamentos, as condições e os modos de realização da instrução e do ensino (Libâneo, 2008a). Além disso, é uma matéria de estudo fundamental na formação profissional docente e um meio de trabalho a partir do qual os professores e professoras organizam a atividade de ensino, em função da aprendizagem e do desenvolvimento integral de estudantes.

Nesse sentido, alguns estudos vêm se dedicando à didática, relacionando-a com o ensino (Libâneo, 2008b; Melo; Urbanetz, 2008; Veiga, 2008c; Castanho, 2006; Damis, 2006 entre outros), a pesquisa (Gatti, 2008; Bittar, 2005), a educação superior (Veiga, 2008a), a pós-graduação (Marin, 2003; Veiga et al., 2008b), a formação de professores (Brzezinski; Pimenta, 2001; Ramalho et al., 2002; Alvarado Prada; Longarezi; Vieira, 2009; André, 2009); outros ainda ao estado da arte da didática (Libâneo, 2008b; Pimenta; Anastasiou, 2002; André, 2002, 2008; Garrido; Brzezinski, 2005). Entretanto, esses resultados parecem não ter alterado significativamente a condição da didática, tanto no campo do ensino quanto no investigativo e profissional.

No campo do ensino e da formação para o ensino na graduação, alguns estudos (Gatti; Barretto, 2009; Libâneo, 2010; Sguarezi, 2010; entre outros) têm diagnosticado a condição da didática em relação aos currículos dos cursos de Pedagogia e Licenciatura, o que permitiu verificar que a didática tem enfrentado diversos problemas: pequena carga horária em relação às demais disciplinas; empobrecimento do campo da didática no currículo dos cursos, cedendo lugar para outras disciplinas (sociologia da educação, psicopedagogia, história da educação, formação docente etc.); desarticulação da didática tanto em relação a outras disciplinas quanto em relação à unidade teoria-prática inerente ao seu próprio campo; relativo abandono do objeto de estudo clássico da didática, o que se observa nos conteúdos (saberes) sugeridos nas ementas das disciplinas; ausência de uma identidade própria nos cursos lementas genéricas, retóricas; forte caráter instrumental); desarticulação entre conteúdos e metodologias; falta de vínculo dos processos desencadeados pela didática com o cotidiano das escolas (estágio); entre outros.

Sobre a formação para o ensino, a pesquisa de Gatti e Barretto (2009) constata, nas instituições de ensino superior que oferecem as licenciaturas, ausência de um perfil profissional claro de docente; currículos que não se voltam às questões do campo da prática profissional, a seus fundamentos metodológicos e suas formas de trabalhar em sala de aula; currículos que continuam privilegiando os conhecimentos da área específica em detrimento dos conhecimentos didáticos; fragilidade nas concepções e implementações dos estágios; e o predomínio do ensino apostilado. 
No campo investigativo, os estudos procuram levantar o que, sobre o que e o quanto se tem pesquisado e produzido sobre Didática na pós-graduação (Longarezi; Puentes, 2010). Assim, o presente trabalho foi realizado com o objetivo de analisar o lugar que a Didática tem ocupado, bem como de identificar os veículos nos quais se tem divulgado as pesquisas e produções dos programas de pós-graduação em Educação no estado de Minas Gerais, no período de 2004 a 2008.

A pós-graduação em Educação nesse estado está próxima de comemorar os quarenta anos da criação, em 1971, do mestrado em Educação da Universidade Federal de Minas Gerais - UFMG, um dos primeiros de seu tipo no interior do Brasil. Desde então, foram criando-se e consolidando-se novos programas em todo o estado com a finalidade de contribuir para o desenvolvimento da educação, por intermédio do aprofundamento de estudos, da realização de pesquisas, da produção de conhecimento e da formação de profissionais da educação.

Atualmente estão em funcionamento em Minas Gerais um total de onze programas de pós-graduação em Educação credenciados pela Capes, dos quais apenas oito deles constituíram a amostra (PUC/MG, UFMG, UFU, UNIUBE, UFJF, UNINCOR, CEFET e UFSJ). Os programas em Educação da UEMG e UFV e o mestrado profissionalizante em Ensino de Ciências e Matemática da PUC/MG não foram considerados. Os dois primeiros porque são recém constituídos (atividades iniciadas em março de 2009). 0 terceiro porque não é acadêmico e porque tem sua área de concentração nas didáticas específicas ou metodologias do ensino.

Consultando os dados informados nos sites dos oito programas selecionados foram identificados professores vinculados às linhas de pesquisa da didática ou de áreas afins, resultando no seguinte levantamento: treze docentes da PUC/MG, oito da UFMG, vinte e três da UFU, oito da UNIUBE, vinte e cinco da UFJS, nove da UNINCOR, dezoito do CEFET e oito da UFSJ.

Os dados desses professores passaram a compor a fonte de informações da pesquisa mediante o levantamento dos respectivos currículos lattes, nos quais foram identificadas as pesquisas (projetos cadastrados) e produções (artigos em periódicos; livros e capítulos de livros; e trabalhos completos publicados em anais de eventos) correspondentes ao período analisado (2004-2008). Com base no levantamento foi feita, num primeiro momento, a leitura dos títulos, resumos e palavras-chave de cada um deles, o que permitiu identificar, classificar e qualificar esses dados em campos e dimensões da didática.

Consideram-se como campos da Didática o disciplinar, o profissional e o investigativo. No campo disciplinar enquadraram-se os trabalhos que abordam e discutem questões relativas ao desenvolvimento da didática enquanto disciplina acadêmica, ou seja, relativas ao seu ensino; no campo profissional, trabalhos relacionados à formação e 
profissionalização para a docência com base nos saberes didáticos, e no campo investigativo pesquisas que se ocupam do estudo do ensino, dos processos de ensino e aprendizagem, das relações entre ambos processos, da prática docente e da produção de conhecimento novo sobre a Didática.

Tomando como referência o conceito e o objeto de estudo da Didática elaborado por Libâneo (2008), consideram-se como dimensões da didática os fundamentos, as condições e os modos de realização da instrução e do ensino. Os fundamentos consistem no conjunto de saberes, conhecimentos, teorias, tendências, paradigmas, ideias, pensamentos, juízos, discursos, argumentos etc. que obedecem a certas exigências de racionalidade e que são utilizados para justificar, explicar ou embasar as ações didáticas (as condições e os modos), incluindo-se ainda os estudos relacionados ao estado da arte. As condições se enquadram em dois tipos: as externas (relacionadas a sociedade, comunidade, família, políticas educacionais, organização do trabalho pedagógico da escola etc., que condicionam as práticas) e as internas ou relativas à organização do trabalho didático (ambiente educativo: espaço, tempo e recursos), os programas de aprendizagem e o papel educativo do processo docente. Os modos incluem os objetivos, o sistema de conteúdos, os métodos, as atividades e estratégias de aprendizagem, bem como a avaliação, isto é, as formas e as maneiras de se efetivar, do ponto de vista metodológico, o processo de ensino-aprendizagem.

Num segundo momento, foram identificados os veículos de divulgação dessas produções (periódicos, livros e anais de eventos). Dentro de cada um desses veículos foram estabelecidos critérios que permitiram tanto localizar quanto qualificar cada um deles. Para os periódicos foi utilizado o Qualis/Capes² lavaliação referente ao triênio 20072009) que agrupa as revistas em três classificações ( $A, B$ e C ), divididas em oito estratos (A1, A2, B1, B2, B3, B4, B5 e C). Para efeito desse estudo, criou-se uma quarta classificação que inclui os periódicos sem Qualis/Capes.

Os livros, por sua vez, foram classificados em quatro grupos: livros publicados em editoras internacionais, em editoras nacionais, em editoras universitárias e em outras editoras. No primeiro grupo foram agrupadas as publicações de livros e/ou capítulos de livros de editoras estrangeiras. No grupo das editoras nacionais foram concentradas as de circulação e comercialização com abrangência nacional, com tradição de publicação na área de Educação, com catálogo de publicações na área, com conselho editorial próprio interinstitucional e revisores por pares, tais como: Autêntica, Papirus, Vozes,

2. "Qualis é o conjunto de procedimentos utilizados pela Capes para estratificação da qualidade da produção intelectual dos programas de pós-graduação. [...] A estratificação da qualidade dessa produção é realizada de forma indireta [...] Esses veículos são enquadrados em estratos indicativos da qualidade - A1, o mais elevado; $A 2 ; B 1 ; B 2 ; B 3 ; B 4 ; B 5 ; C-$ com peso zero" (Brasil. Capes, 2010). Os critérios de avaliação estão no documento da área de Educação 2009 (Brasil. Capes, 2009). 
Átomo \& Alínea, Champagnat, Argumentum, Mercado de Letras, JMEditora, Loyola, Cortez, entre outras. Nas editoras universitárias, terceiro grupo, enquadraram-se as vinculadas a Instituições de Ensino Superior, de circulação e comercialização às vezes mais restritas do que as nacionais e com conselho editorial próprio. Entre elas incluem-se a Liber-livro, UFOP, UFMG, PUC/MG, EDIPUCRS, EDUFU, Unijuí, Editora Universitária João Pessoa, EDUFES etc. No último grupo, outras editoras, foram selecionadas as de circulação e comercialização restrita, de escassa projeção acadêmica no âmbito nacional na área de Educação, tais como Atrito Arte, Bagaço, Jacintha Editores, RG Editores, entre outras.

Quanto aos anais de eventos foram classificados, de acordo com a abrangência dos congressos, em quatro grupos: internacionais, nacionais, regionais e locais.

\section{A Didática nos projetos de pesquisa}

Levantou-se 412 projetos desenvolvidos ou em desenvolvimento no período de 2004 a 2008, dos quais 158 estavam relacionados a um dos campos da Didática (Tabela 1). Isso representa $38,34 \%$ do total das pesquisas desenvolvidas pelo corpo docente dos programas de pós-graduação no estado vinculados a linhas de pesquisas em Didática ou em áreas afins. Há três instituições (UNIUBE, PUC/MG e UFU) que têm um percentual de projetos na área superior a 49\%, o que indica que a Didática tem sido objeto de investigação sistemática nesses programas. Entretanto, nas cinco outras instituições (UFJF, UFSJ, UNINCOR, CEFET e UFMG) o percentual de pesquisa relacionada à Didática é inferior a $32 \%$, o que revela que na maioria dos programas no estado a didática ocupa menos de um terço do total de projetos vinculados às linhas analisadas.

Tabela 1: Total de projetos e de projetos na área por instituição

\begin{tabular}{|l|c|c|c|}
\hline \multicolumn{4}{|c|}{ Projetos } \\
\hline Instituições & Total de Projetos & Projetos na Área & \% (Pa X Tp) \\
\hline PUC & 47 & 31 & 65,95 \\
\hline UFMG & 39 & 8 & 20,51 \\
\hline UFU & 108 & 53 & 49,07 \\
\hline UNIUBE & 18 & 12 & 66,66 \\
\hline UFJF & 87 & 27 & 31,03 \\
\hline UNINCOR & 22 & 7 & 31,81 \\
\hline CEFET & 71 & 14 & 19,71 \\
\hline UFSJ & 20 & 6 & 30,0 \\
\hline Total & $\mathbf{4 1 2}$ & $\mathbf{1 5 8}$ & $\mathbf{3 8 , 3 4}$ \\
\hline
\end{tabular}

Fonte: pesquisa em tela 
Uma análise por separado dos programas de pós-graduação permite notar que 0 programa da UFMG, com mais de 35 anos de atividade acadêmica e conceito 7 na avaliação da Capes (triênio 2007-2009), não tem na didática um campo forte de investigação lapresenta apenas oito projetos na área no período de cinco anos). Por outro lado, a UNIUBE, um programa pequeno e novo, tem mais de $65 \%$ de seus projetos desenvolvidos na área, talvez porque tem a formação de professores como área de concentração. Outro dado que chama atenção diz respeito ao total de projetos executados ou em execução pela UFU no período, que representa $26 \%$ em relação ao total de projetos desenvolvidos pelas oito instituições analisadas e $34 \%$ em relação ao total de projetos na área. Isto significa que pouco mais de um terço das pesquisas da pós-graduação na área de Didática em Minas Gerais está concentrado nessa instituição universitária.

Uma análise dos dados em relação ao número de professores e professoras ligados às linhas de pesquisas relacionadas à didática mostra que, num período de cinco anos, a média de projetos/professor é de 3,67, da qual apenas 1,41 corresponde aos projetos desenvolvidos na área de didática (Tabela 2). As instituições com menos correlação entre o número total de projetos/professor e de projetos na área de didática são UFSJ, Cefet, UNINCOR e UFMG, que têm de dois a cinco projetos/professor no período e no máximo um projeto/professor na área. Isso significa que metade dos programas analisados encontra-se nesta situação.

Tabela 2: Total de projetos, projetos na área e professores por instituição

\begin{tabular}{|l|c|c|c|c|c|}
\hline \multicolumn{7}{|c|}{ Número de projetos por número de professores } \\
\hline Instituições & $\begin{array}{c}\text { Número de } \\
\text { Professores } \\
\text { (NP) }\end{array}$ & $\begin{array}{c}\text { Total de } \\
\text { Projetos (TPJ) }\end{array}$ & $\begin{array}{c}\text { Total de } \\
\text { Projetos na } \\
\text { Área (TPA) }\end{array}$ & $\begin{array}{c}\text { Média } \\
\text { TPJ/NP }\end{array}$ & $\begin{array}{c}\text { MÉDIA } \\
\text { PJA/NP }\end{array}$ \\
\hline PUC & 13 & 47 & 31 & 3,61 & 2,38 \\
\hline UFMG & 08 & 39 & 8 & 4,87 & 1 \\
\hline UFU & 23 & 108 & 53 & 4,69 & 2,30 \\
\hline UNIUBE & 08 & 18 & 12 & 2,25 & 1,50 \\
\hline UFJF & 25 & 87 & 27 & 3,48 & 1,08 \\
\hline UNINCOR & 09 & 22 & 7 & 2,44 & 0,77 \\
\hline CEFET & 18 & 71 & 14 & 3,94 & 0,77 \\
\hline UFSJ & 08 & 20 & 6 & 2,5 & 0,75 \\
\hline
\end{tabular}

Fonte: Pesquisa em tela 
Por outro lado, as instituições com maior correlação entre o número total de projetos/professor e o número de projetos na área de didática são PUC/MG, UNIUBE, UFU e UFJF, que têm acima de um projeto/professor na área no período compreendido. No caso da PUC/MG e da UNIUBE, $66 \%$ do total dos projetos/professor desenvolvidos no período são na área de didática. Diferentemente, a UFMG e o CFFET são as que menor correlação têm entre o número total de projetos/professor e o número de projetos na área de didática, com $20 \%$.

\section{A didática nas produções acadêmicas dos programas}

Foram levantadas para o período 2.358 publicações, entre artigos em periódicos, livros e capítulos de livros, além de trabalhos completos publicados em anais de congressos científicos, das quais 760 foram identificadas como produções na área da Didática. Isso corresponde a 32,23\%, percentual inferior ao número de projetos vinculados à área de didática quando comparados ao seu total. Apenas duas instituições, a UNIUBE e a UFU, tiveram um percentual expressivo de produções na área em relação ao total de publicações, equivalente a, aproximadamente, $45 \%$. A maioria dos programas analisados (PUC/MG, Cefet, UFMG, UFJF, UFSJ e UNINCOR) tem uma produção na área inferior a um terço do total de produções, variando entre 26 e $31 \%$. 0 programa com menor índice percentual de produção na área foi o da UNINCOR, com 9,32\%. Esses dados são reveladores da pouca produtividade na área de didática no estado de Minas Gerais, uma vez que, embora $38,34 \%$ dos projetos desenvolvidos pelos programas estejam relacionados à área de Didática, seis dos oito programas têm uma produção inferior a um terço do total de suas publicações. Disso decorre outro dado: a pouca vinculação entre o que se indica como intenção de pesquisa nos projetos e o que disso efetivamente resulta em produção.

Considerando a relação entre o número total de projetos (412) e o número total de produções (2.358), observa-se que há uma proporção de 5,72 produções por projeto desenvolvido, o que corresponde a mais de um produto por ano no período analisado. Contudo, essa mesma análise, quando relacionada ao número de produções na área (760) e ao número de projetos na área (158), encontra uma proporção de 4,81 (Tabela 3). Para esse caso, há menos de um produto por ano no mesmo período. 
Tabela 3: Total de produções e produções na área por instituições

\begin{tabular}{|l|c|c|c|}
\hline \multicolumn{4}{|c|}{ Produções } \\
\hline Instituições & Total de produções & Produções na área & \% (PA X TP) \\
\hline PUC & 305 & 79 & 25,90 \\
\hline UFMG & 211 & 57 & 27,01 \\
\hline UFU & 676 & 298 & 44,08 \\
\hline UNIUBE & 160 & 74 & 46,25 \\
\hline UFJF & 373 & 101 & 27,07 \\
\hline UNINCOR & 118 & 11 & 09,32 \\
\hline CEFET & 402 & 105 & 26,11 \\
\hline UFSJ & 113 & 35 & 30,97 \\
\hline total & $\mathbf{2 3 5 8}$ & $\mathbf{7 6 0}$ & $\mathbf{3 2 , 2 3}$ \\
\hline
\end{tabular}

Fonte: pesquisa em tela

Metade dos programas analisados (UFU, Cefet, UFJF e PUC/MG) concentra $76,41 \%$ do total de produção no período. Dessas, a UFU é responsável por aproximadamente $30 \%$ do total de produção. As mesmas quatro instituições que representam $50 \%$ dos programas analisados, em relação à produção na área, concentram também o maior índice de produção em relação ao total produzido na área $(76,71 \%)$. Novamente o programa da UFU apresenta o maior percentual, com 40\% do total de produção na área.

Observa-se, pois, que, se os dados aqui apresentados são todos extraídos das linhas de pesquisa da Didática ou das áreas afins e metade dos programas analisados concentram quase $80 \%$ da produção na área de didática, há um enorme desequilíbrio da produção na área entre uns programas e outros. A outra metade tem apenas pouco mais de $20 \%$.

Uma análise desses dados em relação ao número de professores ligados às linhas de pesquisas relacionadas à Didática mostra que, num período de cinco anos, a média de produção por professor é de 21,05, o que representa 5,32 produtos por ano por professor (Tabela 4). Entretanto, a média de produção na área, em relação ao número de professores, é de 6,78, o que equivale a uma produção anual de 1,35, um terço do total de produção na área por professor/ano.

Três instituições (UNINCOR, UFJF e UFSJ) apresentam menos de um produto/ professor por ano na área, isto é, entre 0,25 a 0,87 publicações/professor/ano. A instituição com menos correlação entre o número total de produções por professor e o 
número de produções na área de didática é a UNINCOR, a qual tem pouco mais de uma produção/professor no período analisado, em média 0,25 produtos por ano.

Tabela 4: Total de produções, produções na área e professores por instituições

\begin{tabular}{|l|c|c|c|c|c|}
\hline \multicolumn{7}{|c|}{ Número de produções por número de professores } \\
\hline Instituições & $\begin{array}{c}\text { Número de } \\
\text { professores } \\
\text { (NP) }\end{array}$ & $\begin{array}{c}\text { Total de } \\
\text { produção } \\
\text { (TP) }\end{array}$ & $\begin{array}{c}\text { Total de } \\
\text { produção na } \\
\text { área (TPA) }\end{array}$ & $\begin{array}{c}\text { Média } \\
\text { TP/NP }\end{array}$ & $\begin{array}{c}\text { Média } \\
\text { TPA/NPA }\end{array}$ \\
\hline PUC & $\mathbf{1 3}$ & 305 & 79 & $\mathbf{2 3 , 4 6}$ & $\mathbf{6 , 0 7}$ \\
\hline UFMG & $\mathbf{0 8}$ & 211 & 57 & $\mathbf{2 6 , 3 7}$ & $\mathbf{7 , 1 2}$ \\
\hline UFU & $\mathbf{2 3}$ & 676 & 298 & $\mathbf{2 9 , 3 9}$ & $\mathbf{1 2 , 9 5}$ \\
\hline UNIUBE & $\mathbf{0 8}$ & 160 & 74 & $\mathbf{2 0}$ & $\mathbf{9 , 2 5}$ \\
\hline UFJF & $\mathbf{2 5}$ & 373 & 101 & $\mathbf{1 4 , 9 2}$ & $\mathbf{4 , 0 4}$ \\
\hline UNINCOR & $\mathbf{0 9}$ & 118 & 11 & $\mathbf{1 3 , 1 1}$ & $\mathbf{1 , 2 2}$ \\
\hline CEFET & $\mathbf{1 8}$ & 402 & 105 & $\mathbf{2 2 , 3 3}$ & $\mathbf{5 , 8 3}$ \\
\hline UFSJ & $\mathbf{0 8}$ & 113 & 35 & $\mathbf{1 4 , 1 2}$ & $\mathbf{4 , 3 7}$ \\
\hline Total & $\mathbf{1 1 2}$ & $\mathbf{2 3 5 8}$ & $\mathbf{7 6 0}$ & $\mathbf{2 1 , 0 5}$ & $\mathbf{6 , 7 8}$ \\
\hline
\end{tabular}

Fonte: pesquisa em tela

Por outro lado, UFU, UFMG, PUC/MG e CEFET têm uma média de produção por número de professores superior à média geral, que varia entre 22,33 e 29,39, equivalente a seis produtos por professor por ano aproximadamente. Em relação à média de produção na área por número de professores, UFU, UNIUBE e UFMG superam a média geral, tendo a UFU quase o dobro dessa média, com duas publicações e meia na área por professor/ano.

Os dados mostram que tanto a relação entre o número de projetos na área e o número de professores quanto a relação entre o número de produções na área e de professores é similar, na ordem de um terço. Se esse conjunto de dados relaciona-se ao que se tem pesquisado e produzido dentro das linhas dos programas de pós-graduação da Didática ou áreas afins, entende-se que esse percentual revela a pouca expressividade da Didática como campo de investigação e de produção de conhecimento. 


\section{Qualificação dos projetos e das produções na área com enfoque para os Campos da Didática}

Quando qualificados os projetos e produções quanto aos campos da Didática, observa-se um predomínio de pesquisas $(64,55 \%)$ e publicações $(55,52 \%)$ relacionadas ao campo profissional, o que significa uma concentração dos estudos relacionados a formação e profissionalização para a docência. 0 campo investigativo concentra o segundo maior percentual, com $32,27 \%$ dos projetos e $41,18 \%$ das produções, revelando ainda um enfoque dos trabalhos na produção de novos conhecimentos vinculado à aprendizagem, ao ensino e à prática docente. 0 campo disciplinar, no entanto, é o que menos interesse investigativo representa, com 3,16\% dos projetos e 3,28\% da produção. Tem sido, portanto, objeto de poucos estudos a Didática enquanto disciplina acadêmica vinculada aos programas de formação para o ensino. A tabela abaixo apresenta esses dados em seus valores absolutos.

Tabela 5: Projetos e produções por programas em relação aos campos da didática

\begin{tabular}{|c|c|c|c|c|c|c|c|c|}
\hline \multirow{4}{*}{ 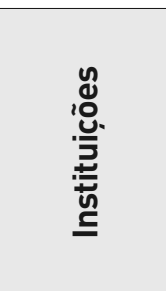 } & \multicolumn{8}{|c|}{ Projetos e produções por instituição em relação aos campos } \\
\hline & \multicolumn{8}{|c|}{ Campos da didática } \\
\hline & \multicolumn{2}{|c|}{ Disciplinar } & \multicolumn{2}{|c|}{ Profissional } & \multicolumn{2}{|c|}{ Investigativo } & \multirow{2}{*}{$\begin{array}{l}\text { Total de } \\
\text { projetos }\end{array}$} & \multirow{2}{*}{$\begin{array}{l}\text { Total de } \\
\text { produção }\end{array}$} \\
\hline & projeto & produção & projeto & produção & projeto & produção & & \\
\hline PUC & 05 & 15 & 22 & 41 & 04 & 23 & 31 & 79 \\
\hline UFMG & - & - & 05 & 32 & 03 & 25 & 08 & 57 \\
\hline UFU & - & 05 & 30 & 172 & 23 & 121 & 53 & 298 \\
\hline UNIUBE & - & - & 11 & 46 & 01 & 28 & 12 & 74 \\
\hline UFJF & - & 01 & 19 & 72 & 08 & 28 & 27 & 101 \\
\hline UNINCOR & - & - & 05 & 10 & 02 & 01 & 07 & 11 \\
\hline CEFET & - & 04 & 07 & 37 & 07 & 64 & 14 & 105 \\
\hline UFSJ & - & - & 03 & 12 & 03 & 23 & 06 & 35 \\
\hline TOTAL & 05 & 25 & 102 & 422 & 51 & 313 & 158 & 760 \\
\hline
\end{tabular}

Fonte: pesquisa em tela

A análise da preeminência dos campos no interior dos diferentes programas indica algumas disparidades em relação aos resultados gerais apresentados acima. Observa-se, 
pois, que a PUC/MG é a única instituição que desenvolve projetos no campo disciplinar e, por isso, torna-se responsável por $60 \%$ de toda a produção no mesmo. 0 Cefet, embora tenha igual quantidade de projetos relacionados aos campos profissional e investigativo, tem quase o dobro de produções no campo investigativo, em relação às produções no campo profissional.

\section{Qualificação dos projetos e das produções na área com enfoque para as dimensões da Didática}

Quanto às dimensões da Didática, observa-se que prevalecem projetos $(46,20 \%)$ e produções $(53,02 \%)$ relacionados aos fundamentos. Há predomínio de estudos voltados para a análise do conjunto de saberes, conhecimentos, teorias, estados da arte, entre outros, que constituem a base das fundamentações teóricas para a explicação das ações Didáticas. A dimensão da Didática relacionada aos modos concentra $36,07 \%$ dos projetos e $31,18 \%$ das produções, de maneira que estudos preocupados com as formas e maneiras de se realizar a organização Didática do processo de ensino-aprendizagem têm sido objeto de aproximadamente um terço das pesquisas realizados na área. As condições representam a dimensão menos expressiva nos estudos, com $17,72 \%$ dos projetos e $15,78 \%$ das produções na área. Os condicionantes externos (políticas educacionais, o vínculo do ensino com a sociedade, a comunidade, a família etc.) e/ou os internos (o ambiente educativo, os programas de aprendizagem etc.) não têm sido objeto de interesse. A tabela abaixo apresenta esses dados em seus valores absolutos.

Tabela 6: Projetos e produções por programas em relação às dimensões da didática

\begin{tabular}{|c|c|c|c|c|c|c|c|c|}
\hline \multirow{4}{*}{ 逗 } & \multicolumn{8}{|c|}{ Projetos e produções por instituição em relação às dimensões } \\
\hline & \multicolumn{8}{|c|}{ Dimensões da didática } \\
\hline & \multicolumn{2}{|c|}{ Fundamentos } & \multicolumn{2}{|c|}{ Condições } & \multicolumn{2}{|c|}{ Modos } & \multirow{2}{*}{$\begin{array}{l}\text { Total de } \\
\text { projetos }\end{array}$} & \multirow{2}{*}{$\begin{array}{l}\text { Total de } \\
\text { produção }\end{array}$} \\
\hline & projeto & produção & projeto & produção & projeto & produção & & \\
\hline PUC & 13 & 36 & 10 & 33 & 08 & 10 & 31 & 79 \\
\hline UFMG & 02 & 19 & 02 & 12 & 04 & 26 & 8 & 57 \\
\hline UFU & 22 & 182 & 01 & 11 & 30 & 105 & 53 & 298 \\
\hline UNIUBE & 07 & 51 & 01 & 08 & 04 & 15 & 12 & 74 \\
\hline UFJF & 11 & 61 & 10 & 16 & 06 & 24 & 27 & 101 \\
\hline
\end{tabular}


Tabela 6: continuação

\begin{tabular}{|c|c|c|c|c|c|c|c|c|}
\hline \multirow{4}{*}{ 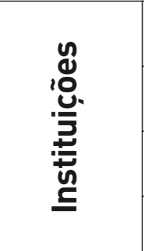 } & \multicolumn{8}{|c|}{ Projetos e produções por instituição em relação às dimensões } \\
\hline & \multicolumn{8}{|c|}{ Dimensões da didática } \\
\hline & \multicolumn{2}{|c|}{ Fundamentos } & \multicolumn{2}{|c|}{ Condições } & \multicolumn{2}{|c|}{ Modos } & \multirow{2}{*}{$\begin{array}{l}\text { Total de } \\
\text { projetos }\end{array}$} & \multirow{2}{*}{$\begin{array}{l}\text { Total de } \\
\text { produção }\end{array}$} \\
\hline & projeto & produção & projeto & produção & projeto & produção & & \\
\hline PUC & 13 & 36 & 10 & 33 & 08 & 10 & 31 & 79 \\
\hline UFMG & 02 & 19 & 02 & 12 & 04 & 26 & 8 & 57 \\
\hline UFU & 22 & 182 & 01 & 11 & 30 & 105 & 53 & 298 \\
\hline UNIUBE & 07 & 51 & 01 & 08 & 04 & 15 & 12 & 74 \\
\hline UFJF & 11 & 61 & 10 & 16 & 06 & 24 & 27 & 101 \\
\hline UNINCOR & 04 & 07 & 01 & 03 & 02 & 01 & 7 & 11 \\
\hline CEFET & 09 & 36 & 03 & 37 & 02 & 32 & 14 & 105 \\
\hline UFSJ & 05 & 11 & - & - & 01 & 24 & 6 & 35 \\
\hline Total & 73 & 403 & 28 & 120 & 57 & 237 & 158 & 760 \\
\hline
\end{tabular}

Fonte: pesquisa em tela

A análise da preeminência das dimensões no interior dos diferentes programas indica algumas disparidades em relação aos resultados gerais apresentados acima. Observa-se que $71,42 \%$ dos projetos relacionados às condições estão concentrados, em igual proporção, nos programas da PUC/MG e da UFJF, o que é relevante, uma vez que esta dimensão é a de menor interesse investigativo no estado. Esse percentual elevado se repete nas produções das mesmas instituições; já no CEFET, cujo índice de projetos é pequeno, o número de produções relacionadas às condições é elevado, de $30,83 \%$. Além disso, esse último programa, independentemente das dimensões nas quais os projetos estão relacionados, apresenta uma produção relativamente equitativa nas três. No caso da UFU, chama a atenção o fato de ter maior número de publicações na dimensão dos fundamentos, embora a maior quantidade de projetos esteja relacionada à dimensão dos modos. 


\section{Campos e dimensões da Didática: qualificação dos projetos e produções na área}

Uma análise que cruza as informações relacionadas aos campos e dimensões da Didática, no que diz respeito aos projetos de pesquisa desenvolvidos no período (Tabela 3), aponta o predomínio de pesquisas no campo profissional relacionado à dimensão dos fundamentos $(52,94 \%)$, seguido do campo investigativo relacionado à dimensão dos modos (50,98\%). Dessa forma, observa-se uma preponderância de estudos teóricos sobre profissionalização e formação docente; bem como a elaboração de conhecimento didático sobre metodologias de ensino.

A dimensão das condições, independentemente de qualquer um dos três campos, é a que menos interesse tem despertado enquanto objeto de pesquisa; portanto, têm sido negligenciados os aspectos vinculados às condições externas e internas necessárias para a efetivação do trabalho didático.

Chama atenção a ausência de estudos no campo disciplinar associados a análises das condições e dos modos. No campo disciplinar, 100\% dos projetos de pesquisa estão vinculados à dimensão dos fundamentos, ou seja, no que diz respeito às pesquisas sobre a Didática enquanto disciplina acadêmica, apenas se realizaram estudos de caráter teórico.

Tabela 7: Qualificação dos projetos na área em valor absoluto/percentagem, considerando os campos da didática

\begin{tabular}{|c|c|c|c|c|}
\hline $\begin{array}{l}\text { Campos da } \\
\text { didática }\end{array}$ & Total & $\begin{array}{c}\text { Dimensões da } \\
\text { didática }\end{array}$ & $\begin{array}{c}\text { Valor } \\
\text { absoluto }\end{array}$ & $\begin{array}{c}\text { Valor } \\
\text { percentual }\end{array}$ \\
\hline & \multirow{3}{*}{5} & fundamentos & 5 & 100 \\
\hline & & condições & - & - \\
\hline & & modos & - & - \\
\hline \multirow{3}{*}{ Profissional } & \multirow{3}{*}{102} & fundamentos & 54 & 52,94 \\
\hline & & condições & 17 & 16,66 \\
\hline & & modos & 31 & 30,39 \\
\hline \multirow{3}{*}{ Investigativo } & \multirow{3}{*}{51} & fundamentos & 14 & 27,45 \\
\hline & & condições & 11 & 21,56 \\
\hline & & modos & 26 & 50,98 \\
\hline
\end{tabular}

Fonte: pesquisa em tela 
Quanto à produção (Tabela 7), uma análise que articula campos e dimensões permite observar um predomínio da dimensão de fundamentos tanto no campo disciplinar (56\%) quanto no profissional $(70,14 \%)$. Isto significa que as produções têm se concentrado em abordagens teóricas sobre os aspectos da Didática enquanto disciplina acadêmica e enquanto campo de profissionalização e formação docente.

No campo investigativo, observa-se uma preponderância das produções voltadas para as análises dos modos $(50,47 \%)$, o que revela que quando o olhar é para a produção de conhecimentos didáticos, o enfoque é mais no sentido das metodologias de ensino do que na direção das elaborações teóricas ou da análise de condições.

A menor produção no campo profissional, campo de maior interesse, é sobre as condições $(12,32 \%)$ e os modos $(17,06 \%)$, ou seja, os requisitos externos e/ou internos necessários para o ensino e a aprendizagem, bem como as metodologias, não têm sido objeto de muitas publicações quando relacionadas a estudos sobre profissionalização e formação docente. 0 mesmo acontece no campo disciplinar, embora as condições $(24 \%)$ e os modos (20\%) juntos representem quase a metade da produção neste campo.

Tabela 8: Qualificação da produção na área em valor absoluto/percentagem, considerando os campos da didática

\begin{tabular}{|c|c|c|c|c|}
\hline $\begin{array}{l}\text { Campos da } \\
\text { didática }\end{array}$ & Total & $\begin{array}{c}\text { Dimensões da } \\
\text { didática }\end{array}$ & $\begin{array}{c}\text { Valor } \\
\text { absoluto }\end{array}$ & $\begin{array}{c}\text { Valor } \\
\text { percentual }\end{array}$ \\
\hline \multirow{3}{*}{ Disciplinar } & \multirow{3}{*}{25} & fundamentos & 14 & 56,0 \\
\hline & & condições & 06 & 24,0 \\
\hline & & modos & 05 & 20,0 \\
\hline \multirow{3}{*}{ Profissional } & \multirow{3}{*}{422} & fundamentos & 296 & 70,14 \\
\hline & & condições & 52 & 12,32 \\
\hline & & modos & 74 & 17,06 \\
\hline \multirow{3}{*}{ Investigativo } & \multirow{3}{*}{313} & fundamentos & 93 & 29,71 \\
\hline & & condições & 62 & 19,80 \\
\hline & & modos & 158 & 50,47 \\
\hline
\end{tabular}

Fonte: pesquisa em tela

Quando analisados em conjunto, os projetos e produções em relação aos campos e dimensões, observa-se um equilíbrio entre o que se pesquisa e o que se produz nos campos profissional e investigativo, no que se refere às dimensões dos fundamentos, condições e modos. 0 contrário manifesta-se no campo disciplinar, no qual há um 
descompasso entre o que se sugere como pesquisa lapenas na dimensão dos fundamentos) e o que efetivamente se produz (nas três dimensões: fundamentos - $56 \%$, condições - $24 \%$ e modos $-20 \%$. Ainda assim, o percentual de pesquisas e de produções no campo disciplinar é similar quando comparado com os demais campos, o que significa que 0 contraste se dá entre as dimensões do próprio campo, conforme apontado acima.

Em relação aos campos profissional e disciplinar, quando analisada a articulação entre os percentuais de pesquisa e de produção, observa-se que no primeiro concentra-se o dobro de projetos de pesquisa que há no investigativo. Essa diferença não é tão acentuada quando considerada a produção, na qual se percebe que o campo profissional produz $26 \%$ a mais do que o investigativo.

\section{Qualificação das produções com base na análise dos veículos de divulgação}

Quando observados os veículos de divulgação das produções (Tabela 9), constatase que, dos 760 trabalhos publicados no período, 505 (66,44\%) foram em anais de eventos, 124 (16,31\%) em periódicos, 123 (16,18\%) em capítulos de livros e 08 (1,05\%) em livros. Evidencia-se, pois, que a produção está expressivamente concentrada em anais, havendo pouca publicação de livros e uma equitativa produção em periódicos e capítulos de livros.

Tabela 9: Veículos de publicação

\begin{tabular}{|c|c|c|c|c|c|c|c|c|c|}
\hline \multirow{2}{*}{ 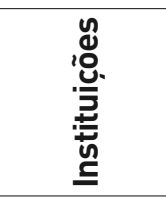 } & \multicolumn{2}{|c|}{ Periódicos } & \multicolumn{2}{|c|}{ Livros } & \multicolumn{2}{|c|}{$\begin{array}{l}\text { Capítulo } \\
\text { de livro }\end{array}$} & \multicolumn{2}{|c|}{$\begin{array}{l}\text { Trabalhos } \\
\text { completos } \\
\text { em anais }\end{array}$} & \multirow[t]{2}{*}{ Total } \\
\hline & $\mathrm{N}^{0}$ & $\%$ & $\mathrm{~N}^{\circ}$ & $\%$ & $N^{0}$ & $\%$ & $N^{0}$ & $\%$ & \\
\hline PUC & 14 & 17,72 & 04 & 5,06 & 14 & 17,72 & 47 & 59,49 & 79 \\
\hline UFMG & 10 & 17,54 & 00 & 00 & 20 & 35,08 & 27 & 47,36 & 57 \\
\hline UFU & 50 & 16,77 & 02 & 0,67 & 46 & 15,43 & 200 & 67,11 & 298 \\
\hline UNIUBE & 03 & 4,05 & 00 & 00 & 06 & 8,10 & 65 & 87,83 & 74 \\
\hline UFJF & 14 & 13,86 & 00 & 00 & 18 & 17,82 & 69 & 68,31 & 101 \\
\hline UNINCOR & 03 & 27,27 & 00 & 00 & 06 & 54,54 & 02 & 18,18 & 11 \\
\hline CEFET & 21 & 20 & 01 & 0,95 & 09 & 8,57 & 74 & 70,47 & 105 \\
\hline UFSJ & 09 & 25,71 & 01 & 2,85 & 04 & 11,42 & 21 & 60 & 35 \\
\hline Total & 124 & 16,31 & 08 & 1,05 & 123 & 16,18 & 505 & 66,44 & 760 \\
\hline
\end{tabular}

Fonte: pesquisa em tela 
Embora já seja expressiva a concentração das produções em anais de eventos, UNIUBE, CEFET e UFU publicam mais do que a média geral das instituições nesse tipo de veículo, variando entre 88 e $67 \%$. Diferentemente, a UNINCOR aparece como uma exceção, pois tem a menor concentração em anais, com apenas $18,18 \%$, e a maior em capítulo de livro, com 54,54\%, o triplo da média geral. A UFMG, por sua vez, tem a segunda menor concentração em anais (47,36\%, também abaixo da média) e a segunda maior em capítulo de livros (35,08\%, pouco mais do que o dobro da média geral). 0 CEFET e a UNIUBE que, como visto, têm uma produção acima da média em anais, têm as menores em capítulo de livro (8,57\% e 8,10\%, respectivamente), praticamente metade da média geral.

Os periódicos, que apresentam um percentual equitativo ao dos capítulos de livros (com aproximadamente $16 \%$ ), aparecem principalmente representados pela UNINCOR $(27,27 \%)$, UFSJ $(25,71 \%)$ e CEFET $(20 \%)$, com percentual acima da média. Contrariamente, a UNIUBE tem quatro vezes menor percentual que a média geral, com apenas $4,05 \%$ de suas publicações nesse veículo. 0 livro, veículo menos utilizado no período para divulgação das pesquisas (com percentual de 1,05\%), é ignorado por metade das instituições (UFMG, UNIUBE, UFJF e UNINCOR). Destaca-se que a PUC é responsável por $50 \%$ dessas publicações, com 04 livros, o que representa cinco vezes mais do que a média, seguida da UFU com $25 \%$.

Uma vez mapeada a distribuição das produções nos diferentes veículos de publicação, foi analisada a qualificação dos mesmos, conforme critérios anteriormente apresentados: anais labrangência dos congressos - internacionais, nacionais, regionais e locais), periódicos (Qualis Capes - A, B, C e sem Qualis), capítulo de livros e livros (classificados por editoras - internacionais, nacionais, universitárias e outras editoras). Dos 505 trabalhos publicados em anais de eventos, 227 (44,95\%) foram em congressos de abrangência nacional (Tabela 10). Congressos internacionais e regionais concentraram 102 publicações cada um $(20,19 \%)$, enquanto anais de congressos locais totalizaram 74 publicações $(14,65 \%)$. Isso revela que praticamente metade dessas publicações está concentrada em anais de congressos nacionais e que há um equilíbrio entre as publicações em anais internacionais e regionais. 
Tabela 10: Qualificação dos anais pela abrangência dos congressos

\begin{tabular}{|c|c|c|c|c|c|c|c|c|c|}
\hline \multirow{3}{*}{ 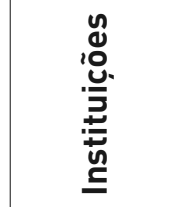 } & \multicolumn{9}{|c|}{ Congressos } \\
\hline & \multicolumn{2}{|c|}{ Internacional } & \multicolumn{2}{|c|}{ Nacional } & \multicolumn{2}{|c|}{ Regional } & \multicolumn{2}{|c|}{ Local } & \multirow{2}{*}{$\begin{array}{l}\text { Total } \\
\mathrm{N}^{\circ}\end{array}$} \\
\hline & $\mathrm{N}^{\circ}$ & $\%$ & $\mathrm{~N}^{0}$ & $\%$ & $N^{\circ}$ & $\%$ & $\mathrm{~N}^{\circ}$ & $\%$ & \\
\hline PUC & 05 & $10,63 \%$ & 12 & $25,53 \%$ & 30 & $63,82 \%$ & 0 & 0 & 47 \\
\hline UFMG & 11 & $40,74 \%$ & 13 & $48,14 \%$ & 02 & $7,40 \%$ & 01 & $3,70 \%$ & 27 \\
\hline UFU & 33 & $16,50 \%$ & 97 & $48,05 \%$ & 46 & $23 \%$ & 24 & $12 \%$ & 200 \\
\hline UNIUBE & 17 & $26,15 \%$ & 19 & $29,23 \%$ & 12 & $18,46 \%$ & 17 & $26,15 \%$ & 65 \\
\hline UFJF & 20 & $28,98 \%$ & 25 & $36,23 \%$ & 07 & $10,14 \%$ & 17 & $24,63 \%$ & 69 \\
\hline UNINCOR & 01 & $50 \%$ & 0 & 0 & 0 & 0 & 01 & $50 \%$ & 02 \\
\hline CEFET & 13 & $17,56 \%$ & 50 & $67,56 \%$ & 05 & $6,75 \%$ & 06 & $8,10 \%$ & 74 \\
\hline UFSJ & 02 & $9,52 \%$ & 11 & $52,38 \%$ & 0 & 0 & 08 & $38,09 \%$ & 21 \\
\hline Total & 102 & $20,19 \%$ & 227 & $44,95 \%$ & 102 & $20,19 \%$ & 74 & $14,65 \%$ & 505 \\
\hline
\end{tabular}

Fonte: pesquisa em tela

CEFET, UFSJ, UFU e UFMG são os principais responsáveis pelo predomínio de publicações em anais de congressos nacionais, e o CEFET concentra mais de $67 \%$ de suas produções nesse tipo de veículo. Todos têm um índice superior a 48\%. A PUC, por sua vez, é a única instituição que foge da regra, com percentual bem abaixo da média $(25,53 \%)$ no caso dos congressos nacionais e três vezes acima da média no caso de publicações em anais de congressos regionais (63,82\%).

Há três outros aspectos que chamam a atenção. Primeiramente, o fato da UFSJ (38,09\%), da UNIUBE $(26,15 \%)$ e da UFJF $(24,63 \%)$ apresentarem um percentual elevado de publicações em congressos locais, bem acima da média (14,65\%). Em segundo lugar, a baixa publicação da UNINCOR em anais de congresso, uma vez que, como visto anteriormente, concentra suas publicações em capítulos de livros. Em terceiro, a grande concentração das publicações da UFMG em anais de congressos nacionais $(48,14 \%)$ e internacionais $(40,74 \%)$.

Os resultados das pesquisas no campo da Didática são, como visto, majoritariamente divulgados em congressos. Contudo, esses trabalhos não têm se convertido, como era de supor na maioria dos casos, em artigos científicos, capítulos de livros ou livros completos. Os dados demonstram que apenas $16,31 \%$ dos produtos são publicados em periódicos. Em valor absoluto, isso se traduz em 124 publicações distribuídas de forma desigual nas classificações Qualis/Capes (Capes, 2009). Foi possível observar 
que $65,32 \%$ dos artigos publicados no período estão concentrados em periódicos Qualis B (Tabela 11). Essa classificação concentra o maior número de revistas qualificadas. Na grande área de humanas são 940 periódicos contra apenas 130 classificadas como A. Isso nos indica que a produção sobre Didática está fortemente concentrada em revistas pior avaliadas pela Capes, embora a classificação B englobe 5 estratos - B1, B2, B3, B4 e B5 - que variam de forma descendente de 70 a 10 pontos.

Em revistas Qualis A as produções na área representam apenas $16,12 \%$ das publicações em periódicos (Tabela 11). Em proporção maior, com 18,53\%, estão as publicações em periódicos Qualis C ou sem Qualis. É importante lembrar que a classificação da revista em Qualis $C$ a coloca numa condição de pontuação nula, similar àquelas não qualificadas. Ou seja, 18,53\% das produções da Didática não estão sendo pontuadas, 0 que talvez possa indicar seu inexpressivo valor acadêmico e sua baixa circulação.

A divulgação de pesquisas na área de Didática, além de se utilizar pouco dos periódicos, com apenas 16,31\% (Tabela 9), utiliza os de menor expressão (Tabela 11), quando considerados os de valoração baixa ou nula (B3, B4, B5, C e sem qualificação). Esse fenômeno se manifesta, sobretudo, no caso da UNIUBE $(66,66 \%)$ e da UNINCOR $(66,66 \%)$, que têm dois terços de suas produções em periódicos sem Qualis. Entretanto, o que se dá como regularidade, quando analisado o conjunto dos programas, não corresponde à UFMG, que tem metade de suas produções distribuídas em periódicos $\mathrm{A}$.

Tabela 11: Qualificação dos periódicos concentrada em apenas três indicadores do qualis

\begin{tabular}{|c|c|c|c|c|c|c|c|c|c|}
\hline \multirow{3}{*}{ 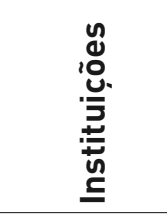 } & \multicolumn{9}{|c|}{ Periódicos/QUALIS-Capes } \\
\hline & \multicolumn{2}{|c|}{ A } & \multicolumn{2}{|c|}{ B } & \multicolumn{2}{|c|}{ C } & \multicolumn{2}{|c|}{ Sem Qualis } & \multirow{2}{*}{ Total } \\
\hline & $\mathrm{N}^{0}$ & $\%$ & $\mathrm{~N}^{0}$ & $\%$ & $\mathrm{~N}^{\circ}$ & $\%$ & $\mathrm{~N}^{0}$ & $\%$ & \\
\hline PUC & 02 & $14,28 \%$ & 06 & $42,85 \%$ & 0 & 0 & 06 & $42,85 \%$ & 14 \\
\hline UFMG & 05 & $50 \%$ & 05 & $50 \%$ & 0 & 0 & 0 & 0 & 10 \\
\hline UFU & 07 & $14 \%$ & 36 & $72 \%$ & 02 & $4 \%$ & 05 & $10 \%$ & 50 \\
\hline UNIUBE & 0 & 0 & 01 & $33,33 \%$ & 0 & 0 & 02 & $66,66 \%$ & 03 \\
\hline UFJF & 01 & $7,14 \%$ & 10 & $71,42 \%$ & 01 & $7,14 \%$ & 02 & $14,28 \%$ & 14 \\
\hline UNINCOR & 0 & 0 & 01 & $33,33 \%$ & 0 & 0 & 02 & $66,66 \%$ & 03 \\
\hline CEFET & 04 & $19,04 \%$ & 16 & $76,19 \%$ & 0 & 0 & 01 & 4,76 & 21 \\
\hline UFS J & 01 & $11,11 \%$ & 06 & $66,66 \%$ & 0 & 0 & 02 & $22,22 \%$ & 09 \\
\hline Total & 20 & $16,12 \%$ & 81 & $65,32 \%$ & 03 & $2,41 \%$ & 20 & $16,12 \%$ & 124 \\
\hline
\end{tabular}

Fonte: pesquisa em tela 


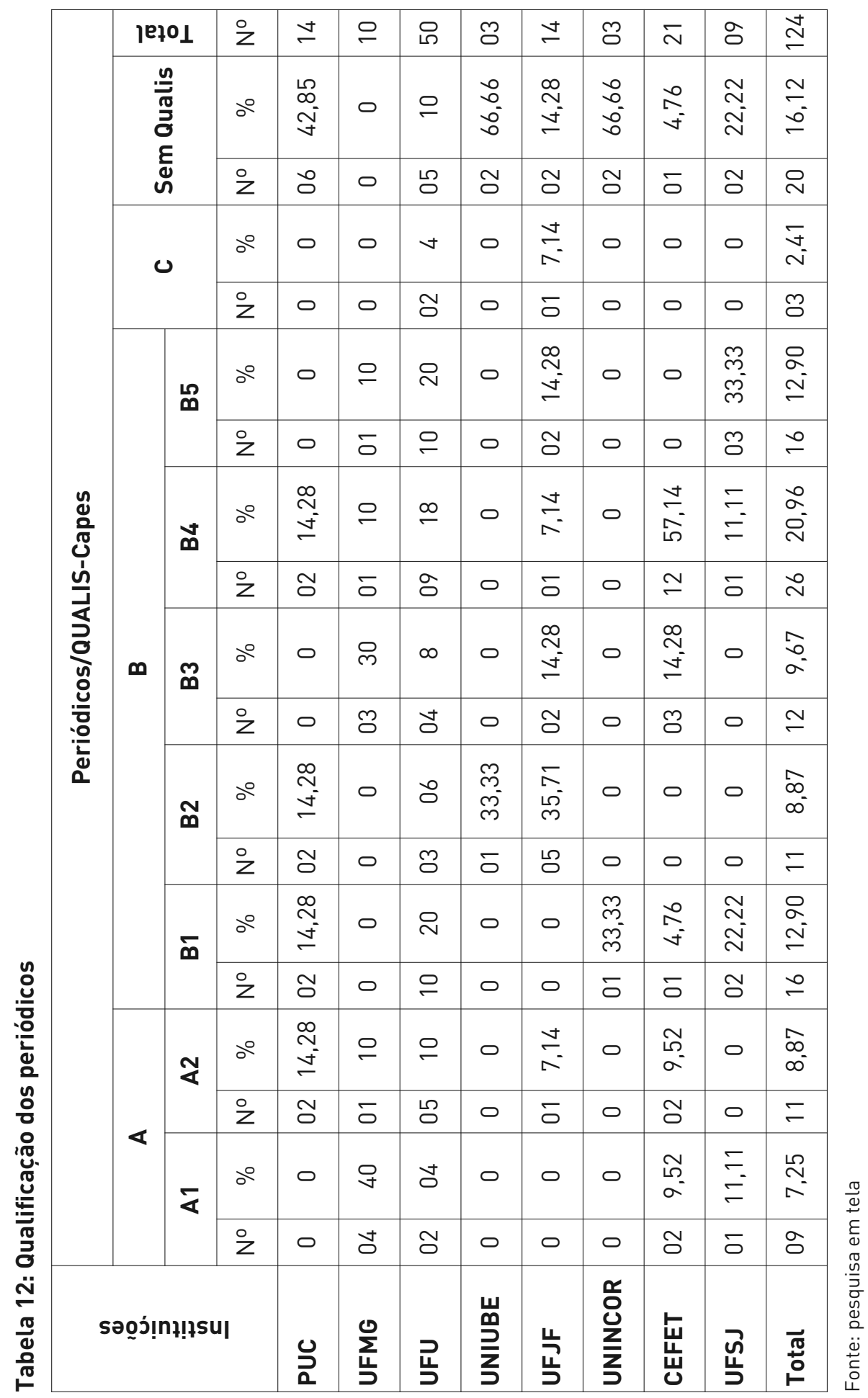


Levando-se em consideração as diferenças de pontuação existentes dentro das próprias classificações com base nos estratos, sobretudo nos periódicos Qualis B (de 70 a 10 pontos), foi analisada a distribuição das produções no campo da Didática não apenas por classificações, mas também por estratos.

Nesse sentido, constatou-se na classificação Qualis A um equilíbrio entre os estratos $A 1(7,25 \%)$ e $A 2(8,87 \%)$, diferentemente da classificação $B$, em que, embora haja certo equilíbrio entre os estratos (com uma média de $11 \%$ ), há um predomínio de publicações em periódicos B4, com 20,96\% (Tabela 8), um percentual expressivo num dos estratos de menor valor. Entretanto, metade dos programas do estado - UFSJ (33,33\%), UFU $(40 \%)$, UFJF $(42,85)$ e UFMG $(50 \%)$ - tem mais de um terço de suas publicações divulgadas em periódicos classificados em estratos de maior valoração (de A1 a B2).

Quanto à divulgação em livros, observou-se que, embora as publicações nesse tipo de veículo seja pouco expressiva $(17,23 \%)$ em relação às demais, ocorrem principalmente em editoras consolidadas, com corpo editorial próprio - sejam elas nacionais $(44,27 \%)$ ou universitárias $(35,87 \%)$, conforme Tabela 13 . Contudo, constatou-se também um percentual relativamente alto $(17,55 \%)$ de publicações da área concentradas em editoras sem conselho editorial, de pouca expressividade ou de restrita circulação (outras editoras). Por fim, chama atenção a escassa inserção da produção científica no campo da Didática no estado no âmbito internacional, uma vez que a publicação em editoras dessa natureza está restrita a apenas 2,29\% do total.

Tabela 13: Qualificação dos livros e capítulo de livros por editora

\begin{tabular}{|c|c|c|c|c|c|c|c|c|c|}
\hline \multirow{3}{*}{ 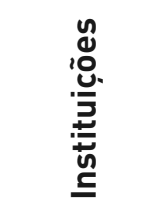 } & \multicolumn{9}{|c|}{ Livros/Capítulo de livros/Editora } \\
\hline & \multicolumn{2}{|c|}{$\begin{array}{c}\text { Editoras } \\
\text { Intenacionais }\end{array}$} & \multicolumn{2}{|c|}{$\begin{array}{l}\text { Editoras } \\
\text { Nacionais }\end{array}$} & \multicolumn{2}{|c|}{$\begin{array}{c}\text { Editoras } \\
\text { Universitárias }\end{array}$} & \multicolumn{2}{|c|}{$\begin{array}{l}\text { Outras } \\
\text { Editoras }\end{array}$} & \multirow{2}{*}{$\begin{array}{c}\text { Total } \\
\mathrm{N}^{0}\end{array}$} \\
\hline & $\mathrm{N}^{0}$ & $\%$ & No & $\%$ & $\mathrm{~N}^{0}$ & $\%$ & $\mathrm{~N}^{\circ}$ & $\%$ & \\
\hline PUC & 02 & $11,11 \%$ & 10 & $55,55 \%$ & 06 & $33,33 \%$ & 0 & 0 & 18 \\
\hline UFMG & 0 & 0 & 16 & $80 \%$ & 02 & $10 \%$ & 02 & $10 \%$ & 20 \\
\hline UFU & 01 & $2,08 \%$ & 15 & $31,25 \%$ & 27 & $56,25 \%$ & 05 & $10,41 \%$ & 48 \\
\hline UNIUBE & 0 & 0 & 03 & $50 \%$ & 01 & $16,66 \%$ & 02 & $33,33 \%$ & 06 \\
\hline UFJF & 0 & 0 & 05 & $27,77 \%$ & 08 & $44,44 \%$ & 05 & $27,77 \%$ & 18 \\
\hline UNINCOR & 0 & 0 & 01 & $16,66 \%$ & 02 & $33,33 \%$ & 03 & $50 \%$ & 06 \\
\hline CEFET & 0 & 0 & 07 & $70 \%$ & 01 & $10 \%$ & 02 & $20 \%$ & 10 \\
\hline UFSJ & 0 & 0 & 01 & $20 \%$ & 0 & 0 & 04 & $80 \%$ & 05 \\
\hline Total & 03 & $2,29 \%$ & 58 & $44,27 \%$ & 47 & $35,87 \%$ & 23 & $17,55 \%$ & 131 \\
\hline
\end{tabular}

Fonte: pesquisa em tela 
Embora metade dos programas - UFMG $(80 \%)$, CEFET $(70 \%)$, PUC $(55,55 \%)$ e UNIUBE $(50 \%)$ - publique mais em editoras nacionais, e três - UFU $(56,25 \%)$, UFJF $(44,44 \%)$ e UNINCOR $(33,33 \%)$ - em editoras universitárias, cinco deles têm quase um terço de suas publicações em outras editoras, sobretudo a UFSJ, que tem $80 \%$ de suas produções concentradas nesse grupo.

\section{Algumas considerações}

Os dados permitem inúmeras discussões, principalmente se analisarmos os resultados no interior dos programas de pós-graduação. Contudo, o objetivo aqui foi o de olhar para a preeminência no conjunto dos programas, buscando entender não apenas o lugar, mas a natureza do que se tem pesquisado e produzido sobre a Didática no estado, e os veículos nos quais se têm divulgado tais produções.

Primeiramente, o estudo diagnosticou que a Didática ocupa, em média, um terço das pesquisas e publicações realizadas por professores vinculados à área em relação ao total no período. Como o universo de pesquisa esteve concentrado nas linhas de pesquisa da área, esses dados revelam que a Didática não tem ocupado centralidade nos estudos dentro das linhas. Por outro lado, em valores absolutos não são poucos os projetos e publicações em Didática, principalmente se considerado o escasso impacto desses estudos na realidade e na prática pedagógica das escolas. Era de se esperar, pelo volume de produção na área, que os processos de ensino-aprendizagem tivessem experimentado uma melhoria.

Observa-se, ainda, dispersão na produção dos professores em relação às linhas de pesquisa nas quais eles estão vinculados, e aos projetos de pesquisa desenvolvidos ou em desenvolvimento. Os professores, aparentemente, estão publicando com uma diversidade maior do que se propõem investigar. As pesquisas e produções realizadas pelos programas de pós-graduação no estado de Minas Gerais, na área de Didática, manifestam um enorme desequilíbrio. 0 primeiro está entre os próprios programas. Enquanto alguns programas pesquisam e publicam com relativa produtividade nessa área, outros ficam aquém das exigências de produção da Capes.

0 segundo desequilíbrio se dá entre os próprios campos e dimensões. Enquanto se pesquisa e se publica muito no campo profissional, na dimensão de fundamentos, se produz menos nos campos investigativo e disciplinar, nas dimensões dos modos e das condições. Nota-se, no interior dos programas de pós-graduação, abundante pesquisa e abundante publicação no campo teórico e, ao mesmo tempo, poucas indagações sobre as condições e os modos de intervenção e de efetivação das práticas pedagógicas. 
Teoriza-se com relativa facilidade, mas se intervém pouco. A aprendizagem e os processos de ensino-aprendizagem ocupam menor lugar enquanto objeto de interesse e de investigação, se comparados ao lugar que formação e profissionalização têm ocupado.

Cabe, portanto, perguntar: qual tem sido o impacto das pesquisas e produções da área nas práticas da Didática, nas práticas do ensino de Didática e, fundamentalmente, nas práticas Didáticas?; por que os estudos estão concentrados em formulações teóricas sobre a formação e profissionalização?; por que os processos de ensinoaprendizagem não se modificam?; por que os modelos de formação de professores e professoras permanecem os mesmos?; e onde precisariam concentrar-se tais estudos para que as pesquisas e produções da área, realizadas no interior dos programas de pós-graduação, estivessem contribuindo para transformações reais nos processos de ensino-aprendizagem?

0 estudo dos veículos de divulgação da produção na área de Didática revelou que dois terços dessa produção estão concentrados em anais de eventos. Mais de um terço desses eventos são regionais e locais, portanto, de menor abrangência, o que concede às publicações um caráter muito restrito em termos de circulação. Os congressos, espaços de divulgação do conhecimento, são bastante abertos e, por isso, têm representado cada vez mais locus de procura para a divulgação oral e escrita dos resultados das pesquisas, tornando-se assim um dos veículos de mais acessibilidade para publicações. Nesse sentido, é esperado que a produção seja publicada mais em anais; no entanto, na proporção levantada, nota-se que o conhecimento sobre Didática tem ficado bastante restrito a esse veículo.

Quanto à publicação em livros, observou-se uma predominância de capítulos de livros em comparação a obras completas, o que de certa forma já era esperado. Não obstante, chama atenção a enorme desproporção, pois se publica dezesseis vezes mais capítulos do que livros na íntegra. Isso pode indicar que as pesquisas não têm produzido conhecimentos substantivos na área dignos de converterem-se em obras científicas, o que se manifesta na quase total ausência de livros de/sobre Didática no estado de Minas Gerais. No que diz respeito ao valor acadêmico atribuído a essas produções, de acordo com os critérios estabelecidos pelo sistema de avaliação da Capes, os capítulos de livro têm hoje o mesmo peso de uma publicação em periódico B2 e, como vimos, têm sido utilizados como veículo de divulgação numa mesma proporção que os periódicos em geral, com aproximadamente $16 \%$ das publicações. Livros completos, por sua vez, têm a mesma pontuação de um artigo em periódico A1, no entanto, representam muito mais trabalho para o autor ou autora que produz uma obra na íntegra, o que indica sua pouca valorização.

A publicação em periódicos representa pouco mais de um sexto do total, o que significa que a cada seis publicações apenas uma é em periódico. Vale ressaltar que 
os periódicos são os veículos de divulgação mais valorizados pela Capes e, talvez por isso, os de mais difícil acesso. 0 grau de dificuldade é diretamente proporcional à qualificação outorgada pela Capes. Ou seja, há mais demanda, e portanto menos espaço, em periódicos $A$, da mesma forma que há menos demanda e maior espaço em periódicos $C$. No que diz respeito à produção no campo da Didática, nota-se que, embora ela se concentre nos estratos B1, B2, B3, B4 e B5 Iconsiderados como estratos de pontuação intermediária), publica-se mais em revistas $C$ ou em periódicos sem qualis, que têm pontuação nula, do que em revistas $A$, que são de maior abrangência e têm mais valor acadêmico. Mesmo entre os $B$, nos quais está o maior percentual das publicações nesse veículo, o número maior está em revistas B4. Esse dado revela que, além das produções da área de Didática serem publicadas entre os periódicos de menor expressividade, estão concentradas num dos estratos de menor valor.

0 estudo utilizou a avaliação da Capes porque é ela que tem estabelecido valores e classificado os veículos, e isso tem definido o movimento e o direcionamento dos produtos nas diferentes áreas. Não faz uma apologia desse sistema de avaliação, como se precisássemos nos adequar a ele de forma acrítica, e reconhece que, como todo sistema de avaliação, tem seus problemas. No entanto, ao final, é ele que acaba qualificando a produção, de forma indireta, quando diz o valor que cada veículo possui. Tomando-o, portanto, como base para ver como a produção da Didática está se comportando dentro desse sistema, observa-se que as produções estão concentradas nos veículos de menor valoração. Supõe-se, pois, que esteja, então, entre os de menor expressividade na área.

Disso decorrem três hipóteses: ou a avaliação da Capes está muito equivocada na qualificação dos veículos de divulgação; ou o que se tem produzido no campo da Didática é de menor qualidade comparado à produção das outras áreas; ou, então, a Didática tem sido marginalizada enquanto área de produção do conhecimento, ficando com os veículos de menor valoração.

\section{Referências}

ALVARADO PRADA, Luis Eduardo; LONGAREZI, Andréa Maturano; VIEIRA, Vania Maria de Oliveira. Concepções de Formação de Professores nos Trabalhos da ANPED 2003-2007. In: REUNIÃO ANUAL DA ANPED, 32., 2009, Caxambu. Anais... Caxambu: ANPED, 2009.

ANDRÉ, Marli Elisa Dalmazo Afonso de (Org.). Formação de professores no Brasil (1990-1998). Brasília: MEC, 2002. (Série Estado do Conhecimento, n. 6)

Tendências da pesquisa e do conhecimento didático no início dos anos 2000. In: EGGERT, Edla et al. (Org.). Trajetórias e processos de ensinar e aprender: Didática e formação de professores. Porto Alegre: EDIPUCRS, 2008. p. 487-499. (v. 1) 
A produção acadêmica sobre formação de professores: um estudo comparativo das dissertações e teses defendidas nos anos 1990 e 2000. Revista Brasileira de Pesquisa sobre formação de professores, Rio de Janeiro, v. 1, n.1, p. 41-56, ago.-dez. 2009.

BITTAR, Marilucia. Pesquisa sobre formação de professores no Brasil e a Pós-graduação em Educação. In: ENCONTRO DE PESQUISA EM EDUCAÇÃO, 3., 2005, Uberaba. Caderno de Resumos... Uberaba, 2005. p. 801-816.

BRASIL. Capes/Qualis. Documento de Área - Educação. 2009. Disponível em <www.capes.gov.br/ qualis>. Acesso em 28 jun. 2010.

BRZEZINSKI, Iria; GARRIDO, Elsa. Análise dos trabalhos do GT Formação de Professores: o que relevam as pesquisas do período 1992-1998. Revista Brasileira de Educação, São Paulo, n. 18, p. 82100, set.-dez. 2001.

CASTANHO, Maria Eugênia. A dimensão intencional do ensino. In: VEIGA, Ilma Passos Alencastro. Lições de Didática. Campinas: Papirus, 2006. p. 35-56.

DAMIS, Olga. Unidade Didática: uma técnica para a organização do ensino e da aprendizagem. In: VEIGA, Ilma Passos Alencastro. Técnicas de ensino: novos tempos, novas configurações. 2. ed. Campinas: Papirus, 2006. p. 105-136.

GARRIDO, Elsa; BRZEZINSKI, Iria. Os caminhos da pesquisa e da docência na atualidade. In: ENCONTRO DE PESQUISA EM EDUCAÇÃO, 3., 2005, Uberaba. Caderno de Resumos... Uberaba, 2005. p. 19.

GATTI, Bernadete Angelina. A pesquisa e a Didática. In: EGGERT, Edla et al. (Org.). Trajetórias e processos de ensinar e aprender: Didática e formação de professores. Porto Alegre: EDIPUCRS, 2008. p. 67-75.

LIBÂNEO, José Carlos. Didática. 28. ed. São Paulo: Cortez, 2008a.

O campo teórico e profissional da Didática hoje: entre Ítaca e o campo das sereias. In: EGGERT, Edla et al. (Org.). Trajetórias e processos de ensinar e aprender: Didática e formação de professores. Porto Alegre: EDIPUCRS, 2008b. p. 234-252.

LONGAREZI, Andréa Maturano; PUENTES, Roberto Valdés. Los campos y dimensiones de la didáctica: un estudio a partir de las investigaciones y producciones de la post-graduación en Brasil. In: CONGRESSO INTERNACIONAL UNIVERSIDAD, 7., 2010, Ciudad de La Habana. Anais... Habana: Universidad de La Habana, 2010. p. 163-174. (v. 1)

MARIN, Alda Junqueira. Didática e Pós-Graduação: aproximações a um tema de estudo. In: MARIN, Alda Junqueira; SILVA, Aída Maria Monteiro; SOUZA, Maria Inês Marcondes de (Org.). Situações Didáticas. Araraquara: JM, 2003. p. 15-46.

MELO, Alessandro de; URBANETZ, Sandra Terezinha. Fundamentos da Didática. Curitiba: IBPEX, 2008.

PIMENTA, Selma Garrido; ANASTASIOU, Léa das Graças Camargos. Pesquisa em Didática -- o movimento recente. In: . (Org). Docência no Ensino Superior. São Paulo: Cortez, 2002. (v. 1)

RAMALHO, Betânia Leite et al. A pesquisa sobre a formação de professores nos Programas de pósgraduação em Educação: o caso do ano 2000. In: REUNIÃO ANUAL DA ANPED, 25., 2002, Caxambu. Anais... Caxambu: ANPED, 2002. 
VEIGA, Ilma Passos Alencastro. As contribuições da Metodologia do Ensino Superior para o desenvolvimento profissional de docentes universitários: questões epistêmicas. In EGGERT, Edla et al. (Org.). Trajetórias e processos de ensinar e aprender: didática e formação de professores. Porto Alegre: EDIPUCRS, 2008a. p. 206-217.

et al. Docência universitária: formação pedagógica no âmbito da pós-graduação. Linhas Críticas, Brasília, v. 14, n. 26, p. 61-78, jan.-jun. 2008b.

Organização didática da aula: um projeto colaborativo de ação imediata. In: (Org.).

Aula: gênese, dimensões, princípios e práticas. Campinas: Papirus, 2008c. p. 267-298.

Recebido em maio de 2011

Aprovado em julho de 2011

Roberto Valdés Puentes, doutor em Educação pela Universidade Metodista de Piracicaba (UNIMEP). Professor adjunto na área de Didática no Programa de Pós-Graduação em Educação na Universidade Federal de Uberlândia (UFU), Campus Santa Mônica/MG. Coordenador do GEPEDI - Grupo de Estudos e Pesquisas em Didática Desenvolvimental e Profissionalização Docente. Publicação recente: Panorama da Didática: Ensino, prática e pesquisa (Papirus, 2011 - coautoria com Andréa Maturano Longarezi). E-mail: robertopuentes@afaced.ufu.br

Andréa Maturano Longarezi, doutora em Educação pela UNESP (Campus de Araraquara). Professora adjunta na área de Didática no Programa de Pós-Graduação em Educação na Universidade Federal de Uberlândia (UFU), Campus Santa Mônica/MG. Coordenadora do GEPEDI - Grupo de Estudos e Pesquisas em Didática Desenvolvimental e Profissionalização Docente e do GEAMA - Grupo de Estudos sobre Aprendizagem na Perspectiva Marxista. Publicação recente: Elementos constituintes e constituidores da formação continuada de professores: contribuições da Teoria da Atividade (Revista Educação e Filosofia, 2011 - coautoria com Patrícia Lopes Jorge Francol. E-mail: andrea.longarezidaterra.com.br; andrealafaced.ufu.br 